\title{
Evaluation of Prevalence and Factors Affecting the Development of Middle Ear Effusion in Patients with Prolonged Intubation in Intensive Care Unit
}

\author{
Denizhan Dizdar ${ }^{1}$, Mehmet Emre Dinç1, Seçkin Ulusoy' ${ }^{1}$ Abdullah Dalğıç ${ }^{1}$, Mehmet Özgür Avınçsal', Cengiz Yumru², \\ Murat Topak' \\ ${ }^{1}$ Clinic of Otolaryngology, Gaziosmanpaşa Taksim Training and Research Hospital, İstanbul, Turkey \\ ${ }^{2}$ Clinic of Anesthesiology and Reanimation, Gaziosmanpaşa Taksim Training and Research Hospital, İstanbul, Turkey
}

\section{ABSTRACT}

Objective: Monitorization of patients in intensive care units requires a multidisciplinary approach. As cooperation with unconscious or intubated patients is often not possible, some conditions may be overlooked. The aim of this study is to reveal the incidence and factors affecting otitis media with effusion in ICU patients intubated longer than 7 days.

Methods: Twenty patients hospitalized in the intensive care unit of the Gaziosmanpaşa Taksim Training and Research Hospital from March to December 2014 were included in the study. The Gaziosmanpaşa Taksim Training and Research Hospital Ethics Committee approved the study according to the Declaration of Helsinki and Good Clinical Practices guidelines. All of the patients included in the study were aged $\geq 18$ years. Patients intubated because of traffic accidents or trauma, patients with a history of chronic otitis media or ear, nose, and throat operations, patients with head and neck tumors, and patients with tympanic membrane perforation, external auditory canal pathology, nasopharyngeal mass, and chronic sinusitis as well as patients with a pathology leading to nasal obstruction, such as nasal polyposis or severe septal deviation, were excluded. After a detailed history by patients' relatives, an otoscopic examination, nasal examination, tympanometry, and acoustic reflex measurements were performed. Ear examination was performed using a conventional portable otoscope.

Results: Among 20 patients, 12 had bilateral effusion (24 out of 40 ears, 60\%). In two patients, a type $C$ tympanogram was obtained (four out of 40 ears, $10 \%)$, and the remaining 12 ears of six patients were normal (30\%). When intubation time is evaluated, among 13 patients intubated longer than 14 days, 11 had effusion (84\%). A significant correlation was found between the duration of intubation and effusion development. Assessing the state of consciousness, 11 of 12 unconscious patients (91\%) were found to have effusion. There was a significant correlation between effusion development and state of consciousness.

Conclusion: In unconscious patients intubated longer than 14 days, the risk of having middle ear effusion is demonstrated to be higher. Consequently, in the periodic follow-up of intensive care patients with prolonged intubation, a routine otoscopic examination has to be considered. (JAREM 2015; 5: 64-7)

Keywords: Otitis media with effusion, intensive care, prolonged intubation

\section{INTRODUCTION}

Monitoring patients in the intensive care unit is an important and difficult issue requiring a multidisciplinary approach. It is often impossible to communicate with unconscious patients and patients attached to a breathing apparatus, and some diseases may be overlooked.

Otitis media with effusion (OME) generally presents with aural fullness and conductive hearing loss. It is more common among children than among adults, and $70 \%-80 \%$ of children have OME at least once in their lives (1). Because the eustachian tube is shorter and more horizontal in children, they are subject to OME more often than adults. In adults, the possibility of developing
OME is lower and the causes of possible OME include sinusitis, smoking cigarettes, and nasopharyngeal cancer (2). OME can aggravate the existing sensorineural hearing loss in adults and increase age-related hearing loss (3). Its incidence is higher in adult intensive care patients (25\%-43\%) $(2,4)$. This possibility particularly increases in patients with nasal intubation. Prolonged intubation is accepted to be more than 14 days. As the duration of intubation extends, the risk and prevalence of OME are expected to increase. In intensive care patients, effusion is affected by nasogastric intubation, age, state of consciousness, and pressure changes in the middle ear (5). This study aims to investigate the prevalence of OME in patients intubated in the intensive care unit for more than 7 days and to reveal possible causes. 


\section{METHODS}

Approval from the Ethics Committee of the Gaziosmanpaşa Taksim Training and Research Hospital was obtained and the study was in accordance with the Declaration of Helsinki and Good Clinical Practice Guidelines (Number: 36/2014). The families of patients were informed regarding the application, and their written informed consents were obtained.

Twenty patients who were hospitalized in the intensive care unit of the Gaziosmanpaşa Taksim Training and Research Hospital between March 2014 and December 2014 were included. All of these patients were orally intubated for more than 7 days. All were older than 18 years and had no history of ear diseases and chronic otitis media. Patients who were intubated because of a traffic accident or trauma and who had a history of ear, nose, and throat operations; head and neck tumor; chronic otitis media; tympanic membrane perforation; external auditory canal pathology; nasopharyngeal mass; chronic sinusitis; or pathology that can prevent nasal passage, such as nasal polyposis or severe septal deviation were excluded from the study. After taking a detailed anamnesis from the relatives of all patients, otoscopic examination, nasal examination, tympanometry, and acoustic reflex measurements were performed.

Ear examinations were performed using a conventional portable otoscope. The external auditory canal of patients having cerumen was cleaned with a curette. Patients with pathology of the external auditory canal were excluded from the study. The color and brightness of the tympanum and the presence of visible effusion were recorded.

A portable AT235h (Interacoustics, DIC 5610, Assens, Denmark) was used for tympanometry and acoustic reflectometry. The obtained tympanogram results were grouped as A, B, and C according to the classification that was defined by Jerger (6) in 1970. Type A was accepted to be normal ears, type B included ears with $O M E$, and type $C$ was accepted to be ears with eustachian dysfunction. Tympanometric examinations were performed on the $7^{\text {th }}$ and $14^{\text {th }}$ days of hospitalization. Following tympanometric examinations, acoustic reflex measurements were conducted. Patients with normal type A tympanum and spectral gradient angle above $95^{\circ}$ in the acoustic reflectometry were evaluated to be normal. The appearance of fluid in the posterior ear level, type B tympanogram, and spectral gradient below $70^{\circ}$ were accepted as effusion.

The patients' age, gender, durations of intubation, state of consciousness, and side of nasogastric tube were recorded.

\section{Statistical Analysis}

Descriptive statistics for continuous variables were demonstrated as mean and standard deviation. Discrete variables were analyzed with Yates corrected chi-square test. The normal distribution hypothesis of the data was tested with the Kolmogorov-Smirnov test. The mean values of variables were analyzed by Student's ttest. Hypotheses were bidirectional, and the value of $p \leq 0.05$ was accepted to be statistically significant. Statistical analyses were performed using SPSS 15.0 for Windows (SPSS Inc.; Chicago, IL, USA) software.

\section{RESULTS}

A total of 20 adult patients were included in the study (11 females and 9 males). The mean age was 66.3 years. Ages ranged from 25 to 83 years. The duration of intubation varied between 7 and 44 days (the mean duration was 21.4 days). A nasogastric catheter was inserted in all patients: on the right side in 10 patients and on the left side in 10 patients. In otoscopic examination, tympanometry, and acoustic reflectometry, otitis media effusion was detected in 12 patients, all of which had effusion in both ears. In two of other patients, type C tympanogram (negative pressure in the middle ear) was found. The ears of six patients were found to be normal in the examination and tympanometry. The risk of effusion was higher in patients whose duration of intubation was more than 7 days. Effusion was observed in 24 of the 40 ears (60\%). Type C tympanogram, i.e., negative pressure, was found in four ears (10\%). Twelve ears were normal (30\%).

It was found that some risk factors could be significant for the development of OME (Table 1). Considering the ages of patients, effusion was detected in three of seven patients who were younger than 60 years. In contrast, in nine of 13 patients who were older than 60 years (69\%), OME was observed. Therefore, although the frequency rate of OME was higher in patients older than 60 years, no statistically significant difference was found $(p=0.23)$. Regarding the state of consciousness, OME was observed in 11 of 12 patients who were unconscious. It was revealed that uncon-

\section{Table 1. Various factors that can cause the development of effusion in the middle ear}

\begin{tabular}{|c|c|c|c|}
\hline & OME Yes (\%) & OME No (\%) & Total \\
\hline \multicolumn{4}{|c|}{ Duration of intubation } \\
\hline 14 and below & $1(14)$ & $6(86)$ & 7 \\
\hline 15 and above & $11(84)^{*}$ & $2(16)$ & 13 \\
\hline Total & 12 & 8 & 20 \\
\hline \multicolumn{4}{|l|}{ Age } \\
\hline$<60$ & $3(42)$ & $4(58)$ & 7 \\
\hline$>60$ & 9 (69) & $4(31)$ & 13 \\
\hline Total & 12 & 8 & 20 \\
\hline \multicolumn{4}{|l|}{ Consciousness } \\
\hline Conscious & $1(12)$ & 7 (88) & 8 \\
\hline Unconscious & $11(91)^{*}$ & $1(9)$ & 12 \\
\hline Total & 12 & 8 & 20 \\
\hline \multicolumn{4}{|c|}{$\begin{array}{l}\text { *Statistically significant }(p<0.05) \\
\text { OME: Otitis media with effusion }\end{array}$} \\
\hline
\end{tabular}


sciousness affected the development of OME ( $p=0.002)$. Moreover, when the durations of intubation were evaluated, it was observed that OME developed in 11 (84\%) of 13 patients who were intubated for more than 14 days. There was a statistically significant relationship between the duration of intubation and development of OME ( $p=0.012)$.

\section{DISCUSSION}

The results of this study suggested that the prevalence of the development of effusion increased in unconscious patients who were hospitalized in the intensive care units and who were intubated for more than 14 days. Our results were consistent with those of other similar studies in the literature $(5,7)$. Two predisposing reasons that may cause the development of effusion can be eustachian tube dysfunction and pathogens reaching the middle ear $(2,4)$. In intubated patients, mechanical ventilation can impair mucociliary function and mucus viscosity and can lead to eustachian dysfunction $(2,4)$. In addition, hypocapnia that occurs because of mechanical ventilation inhibits spontaneous respiration and negatively affects the middle ear pressure $(8,9)$.

Moreover, unconsciousness contributes to eustachian dysfunction by impairing neuromuscular system and swallowing function, and this can cause negative pressure in the middle ear and effusion (5). It has also been found that prolonged intubation (more than 14 days) affects the development of effusion in addition to unconsciousness. This situation may result from nasopharyngeal irritation and duration of edema. In the study of Lin et al. (5), an increase was observed in the development of effusion after 14 days. In another study conducted by Hsiung et al. (9), it was found that the frequency of effusion development decreased when tracheotomy was performed.

Furthermore, some studies revealed that staying in the supine position for a long time and gastroesophageal reflux can also result in bacterial pathogens reaching the middle ear $(4,10)$. The fluids having accumulated in the nasopharynx because of the position can be transferred into the middle ear through the eustachian tube. Moreover, it has been stated that upper respiratory tract infections and sinusitis may be the potential reasons for pathogen migration to the middle ear $(2,10)$.

Although it is rare, the possibility for developing sepsis was reported in intensive care patients with acute otitis media or sinusitis $(11,12)$. In our study, no patient had sepsis, and it was believed that this might have resulted because patients received systematic antibiotherapy and OME was not complicated with suppurative otitis media.

\section{CONCLUSION}

The possibility for developing middle ear effusion was found to be higher in unconscious patients with prolonged intubation of more than 14 days. Thus, periodic otoscopic tympanic membrane examination must be added to the follow-up routines of intensive care patients with prolonged intubation. The risk for developing effusion in the middle ear increases in patients intubated for a long time. Routine otoscopic examinations will be useful with regard to effusion risk in patients intubated for a certain time.

Ethics Committee Approval: Ethics committee approval was received for this study from the ethics committee of Gaziosmanpaşa Taksim Training and Research Hospital (Number: 36/2014).

Informed Consent: Written informed consent was obtained from the parents of the patients who participated in this study.

Peer-review: Externally peer-reviewed.

Author Contributions: Concept - D.D., M.E.D., S.U., M.Ö.A., C.Y., M.T.; Design - D.D., M.E.D., S.U., A.D., M.Ö.A., C.Y., M.T.; Supervision - D.D., M.E.D., S.U., A.D., M.Ö.A., C.Y., M.T.; Data Collection and/or Processing - D.D., M.E.D., S.U., A.D., M.Ö.A.; Analysis and/or Interpretation - D.D.; Literature Review - D.D., M.E.D., S.U., A.D., M.Ö.A.; Writer - D.D., M.E.D., S.U., A.D.; Critical Review - D.D., M.E.D., S.U., A.D., M.Ö.A., M.T.

Conflict of Interest: No conflict of interest was declared by the authors.

Financial Disclosure: The authors declared that this study has received no financial support.

\section{REFERENCES}

1. Teele DW, Klein JO, Rosner B. Epidemiology of otitis media during the first seven years of life in children in greater Boston: a prospective cohort study. J Infect Dis 1989; 160: 83-94. [CrossRef]

2. Christensen L, Schaffer S, Ross SE. Otitis media in adult trauma patients: incidence and clinical significance. J Trauma 1991; 31: 1543-5. [CrossRef]

3. Hamill-Ruth RJ, Ruth RA. Evaluation of audiologic impairment incritically ill patients: results of a screening protocol. Crit Care Med 2003; 31: 2271-77.[CrossRef]

4. Cavaliere F, Masieri S, Liberini L, Proietti R, Magalini SI. Tympanometry for middle-ear effusion in unconscious ICU patients. Eur $\mathrm{J}$ Anaesthesiol 1992; 9: 71-5.

5. Lin CC, Lin CD, Cheng YK, Tsai MH, Chang CS. Middle eareffusion in ICU patients with prolonged endotracheal intubation. Am J Otolaryngol 2006; 27: 109-11. [CrossRef]

6. Jerger J. Clinical experience with impedance audiometry. Arch Otolaryngol 1970; 92: 311-24. [CrossRef]

7. Akdağ M, Çetin M, Baysal ZY, Kadiroğlu AK, Çelik MY, Meriç F. Middle Ear Pressure and Factors Affecting It in Intubated Patients Hospitalized in Intensive Care. Turk Arch Otolaryngol 2014; 52: 47-51. [CrossRef]

8. Derkay CS, Bluestone CD, Thompson AE, Kardatske D. Otitis media in the pediatric intensive care unit: a prospective study. Otolaryngol Head Neck Surg 1989; 100: 292-9.

9. Hsiung KC, Ching CL, Chin YW, Chia DL, Ming HT, Chia SC. Improvement in otitis media with effusion in patients undergoing tracheostomy after prolonged endotracheal intubation. J Otolaryngol Head Neck Surg 2009; 38: 532-6.

10. Palmisano JM, Moler FW, Revesz SM, Custer JR, Koopmann C. Chronic otitis media requiring ventilation tubes in tracheotomized ventilator dependent children. Int J Pediatr Otorhinolaryngol 1994; 30 : 177-82 [CrossRef] 
11. Persico M, Barker GA, Mitchell DP. Purulent otitis media--a "silent" source of sepsis in the pediatric intensive care unit. Otolaryngol Head Neck Surg 1985; 93: 330-4. [CrossRef]
12. Borman KR, Brown PM, Mezera KK, Jhaveri H. Occult fever in surgical intensive care unit patients is seldom caused by sinusitis. Am J Surg 1992; 164: 412-5. [CrossRef] 